\title{
Optimization of signal controlled urban traffic flow using simulation modeling and an experimental design
}

\author{
Benzetim modelleme ve deneysel tasarım ile sinyal kontrollü kentsel trafik \\ akışının en iyilenmesi
}

\author{
Rahime SANCAR EDIS' ${ }^{*}$ (D), PInar MIZRAK ÖZFIRAT2 ${ }^{\text {(D) }}$ \\ 1,2Department of Industrial Engineering, Engineering Faculty, Manisa Celal Bayar University, Manisa, Turkey. \\ rahime.edis@cbu.edu.tr, pinar.ozfirat@cbu.edu.tr
}

Received/Geliș Tarihi: 15.11.2016, Accepted/Kabul Tarihi: 30.12.2016

* Corresponding author/Yazışılan Yazar

doi: $10.5505 /$ pajes.2016.29000 Research Article/Araștırma Makalesi

\begin{abstract}
Traffic flow in urban areas is one of the major problems both for drivers and pedestrians. Traffic congestion and traffic lights constitute a large portion of the time spent in traffic. This wasted time for waiting in traffic also costs countries considerable amount of wasted fuel and hence considerable amount of money. In this study, traffic flow of a road in Izmir, Turkey is considered. In order to decrease all the wasted resources in urban traffic, an experimental design is conducted on the factors affecting the signal controlled traffic flow. The design factors are determined to be signal times of traffic lights, traffic intensity and the speed of vehicles. The effects of these factors on the three performance measures of time in system, waiting time in red light and number of vehicles going out of the system are analyzed. A fractional factorial design is carried out on the 486 design points evaluated using simulation modeling. In results, among the design points, best level of factors to minimize total waiting time in traffic flow are determined.
\end{abstract}

Keywords: Urban traffic flow, Traffic signals, Fractional factorial design, Simulation, Traffic intensity, Traffic optimization

\section{Introduction}

Traffic congestion in urban areas is one of the major problems both for drivers and pedestrians. A person living in an urban area spends a considerable amount of her time with driving and/or waiting in traffic congestion. The wasted time for waiting in traffic also costs considerable amount of wasted fuel and hence considerable amount of money. One of the main reasons of traffic congestion in urban areas is allocating improper durations for traffic signal controls. Therefore, traffic signal controls have been an important research area both for researchers and practitioners.

Traffic signals optimization problem is first introduced in 1950s. Since then, many different solution approaches have been proposed such as empirical solution methods, queue modeling, simulation modeling, and mathematical modeling for many different road networks including intersections, unidirectional/bidirectional networks, highway systems, single lane/multi-lanes etc. [1]. For a detailed review on different methods and strategies for traffic signal optimization, the reader may refer to Papageorgiou et al [2], Mitsakis et al. [3] and Araghiet et al. [4].

Traffic signals have three statuses: Red light, yellow light and green light. Time starting from the red light is on until the next red light is called one cycle. Duration of each status in one cycle
Öz

Kentsel alanlardaki trafik akışı, hem sürücü hem de yayalar için temel problemlerden biridir. Trafik yoğunluğu ve trafik ıșıkları büyük zaman kayıplarına yol açmaktadır. Trafikte beklemelerle oluşan bu zaman kayıplarl, ülkeler için boșa harcanmıs önemli yakıt miktarlarına ve dolayısıyla önemli maliyet kayıplarına neden olmaktadır. Bu çalışmada, Izmir, Türkiye'de bir anayoldaki trafik akıșı incelenmiștir. Kentsel trafikte boșa harcanmıș kaynakları azaltmak üzere; sinyal kontrollü trafik akışın etkileyen faktörleri dikkate alan bir deneysel tasarım çalışması yapılmıştır. Tasarım faktörleri; trafik ışıklarının sinyal süreleri, trafik yoğunluğu ve araçların hızı olarak belirlenmiştir. Bu faktörlerin, sistemde geçirilen süre, kırmızı ıșıta bekleme süreleri ve sistemden çıkabilen araç sayısı amaçları üzerindeki etkileri incelenmiștir. Seçilen 486 tasarım noktasının sonuçları, olușturulan benzetim modelinden elde edilmiștir. Sonuç olarak, tasarım noktalar içinden toplam bekleme süresini en küçükleyen en iyi faktör düzeyleri belirlenmiştir.

Anahtar kelimeler: Kentsel trafik akıșı, Trafik sinyalleri, Kesirli çok etkenli tasarım, Benzetim, Trafik yoğunluğu, Trafik Optimizasyonu

are controlled by the signal. Traffic signals are used in two manners. First one is to show the right-of-way to vehicles at intersection points and the second one is to stop traffic flow for crosswalk. Red/green light durations at intersections should be arranged according to the flow of traffic from both directions. However, durations at crosswalks can be constant to leave enough time for a pedestrian to cross the street.

In most of the approaches in literature, the problem is formulated as setting signal times in order to maximize throughput out of the network or minimize total waiting time/fuel consumption of vehicles. Setting signal times correctly is important to prevent unnecessary delays, decrease queue lengths and increase saturation flow or throughput. There are many different methodologies employed to solve this problem. We may consider these methodologies in two main classes: Numerical modeling approaches and simulation modeling approaches. Due to the stochastic nature of the problem, second group of approaches are more in number compared to the first group. Some of the recent studies in these two groups can be seen in Table 1 below.

In Table 1, three of the studies, Boumediene et al. [5], Febraro and Sacco [1] and Jeihani et al. [11] consider sensitivity analysis on different factors affecting traffic flow. Others try to optimize traffic flow for different types of settings. Mostly considered setting is a road intersection. There are also a few multiintersectional settings considered. 
Table 1: Some of the studies on traffic signal optimization classified according to method used.

Numerical Approaches

\begin{tabular}{l}
\hline $\begin{array}{l}\text { Boumediene et al. [5]-Analysis of Variance, Sensitivity } \\
\text { analysis } \\
\text { Babicheva and Babichev[6]-Mathematical Modeling }\end{array}$ \\
\hline
\end{tabular}
Simulation Approaches

Mirchandani and Head [7]-Adaptive controls

Jahangiri et al. [8]-Simulated Annealing

Mitsakis et al. [3]-Dynamic traffic assignment

Pranevicius and Kraujalis [9]-Fuzzy Logic

Varia et al. [10]-Genetic algorithms

Jeihani et al. [11]-Regression analysis, Sensitivity Analysis

Hu et al. [12]-Cellular Automata

Miscellaneous
Grteher et al. [13]-Queuing theory
Febraro and Sacco [1]-Queuing theory, Sensitivity Analysis
Babicheva [14]-Queuing theory

In this study, an experimental design is conducted on a number of factors affecting traffic flow in an urban road network. The road network handled is in Izmir city which is a major metropolis of Turkey. It includes multi-intersections and multi crosswalk signals. The total distance of the network is $6.7 \mathrm{~km}$. Considering the number of traffic signals and intersections, the problem is very complex. In addition, the road network considered constitutes an important part of traffic congestion in the city.

In order to decrease unnecessary delay times in the system and increase throughput, several factors are identified to be examined. These factors are durations of red/green signals, traffic intensity and vehicle speed. A fractional factorial design frame is built and 486 design points are simulated using ARENA 14.0 [15]. Among these design points, speed of vehicles, red and green signal durations which minimizes total waiting time in the system are found.

The contribution of this paper is twofold. Firstly, it simulates a complex network with several intersections and crosswalks which is rarely studied in the literature. Secondly, it presents a very comprehensive computational study with several design points affecting different performance measures and includes a regression analysis on the performance measures.

The rest of the paper is organized as follows. In section 2 , the problem definition and experimental design frame is given. Section 3 explains simulation modeling in detail. Verification and validation of the model is given in section 4 and, computational results are provided in section 5. Finally, conclusions are given in Section 6.

\section{Problem definition and experimental design frame}

In this study, traffic flow of a road in Izmir, Turkey is considered. A schematic view of the road can be seen in Figure 1. Distance between points A and B is $6.7 \mathrm{kms}$ with six intersections and six crosswalk signals.

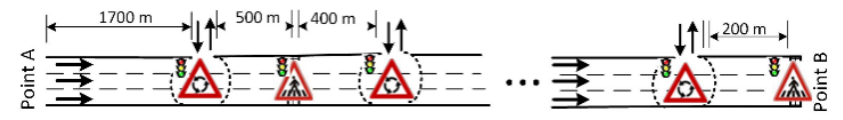

Figure 1: Schematic view of the road under study.

The distances between traffic signals are given in Table 2 . The aim of a traffic light may be due to a crosswalk or an intersection. The type of the signal is also stated in Table 2. In some of the intersections, both entrances and exits take place. However, only entrances are allowed for some other intersections. This property is also given in Table 2. "EE" stands for "both entrance and exit is allowed" whereas "E" stands for "only entrance is allowed".

Table 2: Distance between consecutive traffic signals.

\begin{tabular}{ccc}
\hline Traffic Signal No. & Distance (m) & Signal Type \\
\hline Point A & 0 & - \\
1 & 1700 & Intersection (EE) \\
2 & 500 & Crosswalk \\
3 & 400 & Intersection (EE) \\
4 & 800 & Crosswalk \\
5 & 300 & Crosswalk \\
6 & 400 & Intersection (EE) \\
7 & 100 & Crosswalk \\
8 & 400 & Intersection (E) \\
9 & 200 & Crosswalk \\
10 & 900 & Intersection (EE) \\
11 & 800 & Intersection (EE) \\
12 & 200 & Crosswalk \\
Point B & 0 & - \\
\hline
\end{tabular}

It can be seen from Figure 1 that vehicles enter the road from point A. The first traffic signal is 1700 meters from the entrance. This first signal is for an intersection where both new entries and exits take place. Then 500 meters from the first intersection, there exists a traffic signal for a crosswalk and 400 meter from the crosswalk there is another intersection. Traffic flows in this manner until point 12 where it is also the exit point for the final vehicles in the system. Vehicles may enter or leave the system from any intersection. The only exception is traffic signal 8 (refer to Table 1) where exits are not allowed.

Arrivals of vehicles are generated with the given intensity. Then, vehicles are located at different intersections with specific probabilities to start their journey on the road from the corresponding intersection. The entrance probabilities of vehicles from the intersections are given in Table 3. Exiting probabilities from the intersections can also be seen from the table. For example, $50 \%$ of the entrances occur at Point $\mathrm{A}$ and $60 \%$ of the exits are from Point B.

Table 3: Entrance and exit probabilities of vehicles from the intersections.

\begin{tabular}{ccc}
\hline $\begin{array}{c}\text { Intersection } \\
\text { No }\end{array}$ & $\begin{array}{c}\text { Entrance } \\
\text { probabilities }\end{array}$ & $\begin{array}{c}\text { Exit } \\
\text { probabilities }\end{array}$ \\
\hline Point A & $50 \%$ & - \\
1 & $15 \%$ & - \\
3 & $10 \%$ & $4 \%$ \\
6 & $10 \%$ & $6 \%$ \\
8 & $5 \%$ & - \\
10 & $5 \%$ & $10 \%$ \\
11 & $5 \%$ & $20 \%$ \\
Point B & - & $60 \%$ \\
\hline
\end{tabular}

In this system, traffic intensity is measured and three different levels of intensity are defined for different times of a day. These 
are heavy traffic, medium traffic and light traffic. According to statistical analysis, exponential distribution is accepted to represent the system and $\lambda$ values are found to be $0.8 \mathrm{sec} / \mathrm{car}$, $1 \mathrm{sec} / \mathrm{car}$ and $20 \mathrm{sec} / \mathrm{car}$ for heavy, medium and light traffic respectively. In Table 4, traffic intensities for different times of the day can be seen.

Table 4: Traffic intensity according to the time of day.

\begin{tabular}{ccc}
\hline Time of Day & Traffic Intensity & $\lambda(\mathrm{sec} / \mathrm{car})$ \\
\hline $07: 00-09: 30$ & Heavy & 0.8 \\
$09: 30-16: 30$ & Medium & 1 \\
16:30-19:30 & Heavy & 0.8 \\
19:30-22:30 & Medium & 1 \\
22:30-07:00 & Light & 20 \\
\hline
\end{tabular}

The system defined is considered using simulation modeling. An experimental design frame is set up for the study. Six factors are considered in the frame, which are traffic intensity, crosswalk red light time, crosswalk green light time, intersection red light time, intersection green light time and speed of the vehicle. Design frame, levels of design factors and the total number of design points can be seen in Table 5 .

Table 5: Experimental design frame.

\begin{tabular}{|c|c|c|c|c|c|}
\hline $\begin{array}{c}\text { Traffic } \\
\text { Intensity } \\
\text { (sec/car) }\end{array}$ & $\begin{array}{c}\text { Crossw. } \\
\text { Red } \\
\text { light } \\
\text { (sec) }\end{array}$ & $\begin{array}{c}\text { Crossw. } \\
\text { Green } \\
\text { light } \\
\text { (sec) }\end{array}$ & $\begin{array}{l}\text { Inters. } \\
\text { Red } \\
\text { light } \\
\text { (sec) }\end{array}$ & $\begin{array}{l}\text { Inters. } \\
\text { Green } \\
\text { Light } \\
\text { (sec) }\end{array}$ & $\begin{array}{c}\text { Speed } \\
(\mathrm{km} / \mathrm{h})\end{array}$ \\
\hline$\lambda=0.8$ & $\begin{array}{l}25 \\
35\end{array}$ & $\begin{array}{l}40 \\
50 \\
60\end{array}$ & $\begin{array}{l}20 \\
30 \\
40\end{array}$ & $\begin{array}{l}40 \\
50 \\
60\end{array}$ & $\begin{array}{l}30 \\
40 \\
50\end{array}$ \\
\hline$\lambda=1$ & $\begin{array}{l}25 \\
35\end{array}$ & $\begin{array}{l}40 \\
50 \\
60\end{array}$ & $\begin{array}{l}20 \\
30 \\
40\end{array}$ & $\begin{array}{l}40 \\
50 \\
60\end{array}$ & $\begin{array}{l}40 \\
50 \\
60\end{array}$ \\
\hline$\lambda=20$ & $\begin{array}{l}25 \\
35\end{array}$ & $\begin{array}{l}40 \\
50 \\
60\end{array}$ & $\begin{array}{l}20 \\
30 \\
40\end{array}$ & $\begin{array}{l}40 \\
50 \\
60\end{array}$ & $\begin{array}{l}50 \\
60 \\
70\end{array}$ \\
\hline 3 levels & $\begin{array}{r}2 \text { level } \\
\text { s } \times 3\end{array}$ & $\begin{array}{c}x \quad 3 l \\
\text { vels }=4\end{array}$ & $\begin{array}{l}\text { vels } x \\
6 \text { design }\end{array}$ & $\begin{array}{l}3 \text { leve } \\
\text { points }\end{array}$ & x 3 \\
\hline
\end{tabular}

It can be seen from Table 5 that three levels of traffic intensity are considered. In addition, two levels for crosswalk red light (25 sec. and $35 \mathrm{sec}$.), three levels for crosswalk green light (40 sec., $50 \mathrm{sec}$. and $60 \mathrm{sec}$.), three levels for intersection red light (20 sec., $30 \mathrm{sec}$. and $40 \mathrm{sec}$.) and three levels for intersection green light green light (40 sec., 50 sec. and $60 \mathrm{sec}$.) are considered for all three values of traffic intensity. However, speed levels are changed according to the traffic intensity. For heavy traffic; $30 \mathrm{~km} / \mathrm{hr}, 40 \mathrm{~km} / \mathrm{h}$ and $50 \mathrm{~km} / \mathrm{h}$ are determined as speed levels. For medium traffic; $40 \mathrm{~km} / \mathrm{hr}, 50 \mathrm{~km} / \mathrm{h}$ and $60 \mathrm{~km} / \mathrm{h}$ are determined as speed levels. Lastly, for light traffic; $50 \mathrm{~km} / \mathrm{hr}, 60 \mathrm{~km} / \mathrm{h}$ and $70 \mathrm{~km} / \mathrm{h}$ are determined as speed levels. Since the road network is in the urban area, maximum allowable speed is $70 \mathrm{~km} / \mathrm{h}$. Therefore maximum speed value considered is $70 \mathrm{~km} / \mathrm{h}$.

\section{Simulation modeling}

Simulation model of the system is built in Arena 14.0 [15]. The assumptions of the model can be listed as follows.

- Vehicle arrivals follow an exponential distribution,

- All vehicle entrances to the systems are generated from the same inter-arrival time, and then they are located to different entrance intersections with specific probabilities,

- Time for yellow light is not considered separately, it is included in red light time. In other words, vehicles are assumed to stop at yellow light,

- Vehicle speed is assumed to be constant,

- Passing time of a vehicle from the green light is assumed to be one second.

The frame of the simulation model developed in Arena 14.0 [15] can be seen in Figure 2.

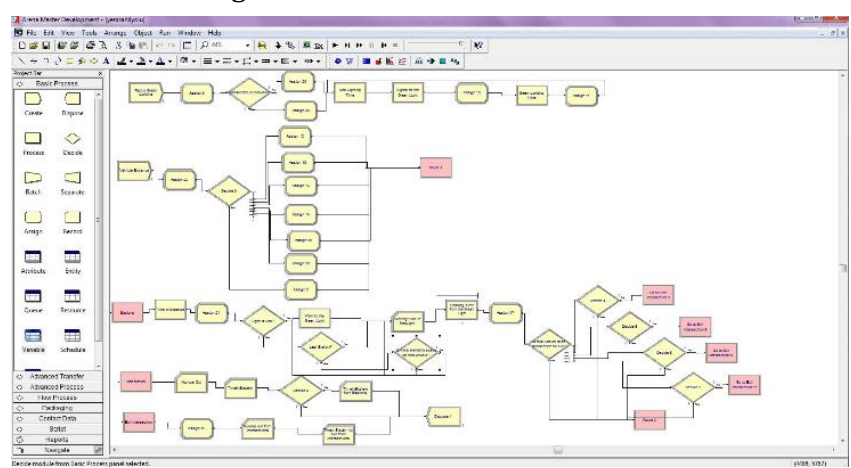

Figure 2: Simulation model view in Arena 14.0 [15].

The simulation model has two controls: one for signaling of the traffic lights on the crosswalks and the intersections and the other is for the flow of the vehicles through the road.

There are 12 traffic signals in the system and the signaling of traffic lights are organized according to the design point parameters of green and red signals of crosswalks and intersections which are given in Table 5 .

The arrivals of vehicles to the system is generated from one source with the same inter-arrival parameter, $\lambda$. Then, with specific probabilities given in Table 3 , the vehicles enter the system from that intersection and an attribute representing the index of the intersection is assigned to the vehicle. While vehicles move along the road, they take the specific amount of distance with the determined parameter of speed for a time period which can be calculated.

When they came up to a traffic signal, there are two alternatives for the state of the traffic signal. If the traffic signal is green, then vehicles pass the traffic signal immediately and continue their journey on the road to the next traffic signal without any delay. If the traffic signal is red, the vehicle waits until the traffic signal turns to green. When the traffic signal turns to green, there are some rules about passing the signal.

- Passing time of a vehicle by the signal is assumed to be 1 second/vehicle. The number of all vehicles waiting for the green signal may not pass due to the limited green signal time. For example, if the time of green signal is 40 seconds, then only 40 vehicles can pass by the signal point on a single green period. If there are more than 40 vehicles waiting at the traffic signal point, the rest of them should wait for the next green signal, 
- Another case is related to the blocking of the area related to traffic jam. If the distance/area to the next traffic light is fully or substantially used by the waiting vehicles on the next traffic light, then because of insufficient place, the number of vehicles passing of the green light may be limited. If there is enough space after the traffic light and if the time of the green light is sufficient for the passing of the vehicle, then this vehicle can pass the light at once or else, they have to wait on the traffic light until the conditions are satisfied.

The exits from the system can only be made from the exit intersection points. The vehicles which pass the traffic light at the exit intersection points may exit from the system with a probability given in Table 3, or continue its journey on the road with the remaining possibilities. The performance measure of the system is the average time spend in the system, so this value is also recorded in the simulation model.

\section{Verification and validation}

Before getting the computational results, verification and validation of the simulation model is done. For verification step, timing of the traffic lights and the behavior of the vehicles along the road are analyzed in detail. The model is run for extreme points and some of the entities are checked for their complete travel. By this way, the model is verified to be operating as expected.

For the validation step, the inputs of the simulation model are set as the inputs of the real system. Then, it is tested for different traffic intensities and the statistics obtained from the model are compared with the real system results. Results of the model can be seen in Table 6 .

In Table 6, average time in system and average time from the first point to the last are recorded (Point A to Point B). For heavy traffic, a vehicle goes from Point A to B in 27 minutes on the average. For medium traffic, this number decreases to 18 minutes and for light traffic it turns out to be 15.26 minutes. In addition, maximum time a vehicle waits in red light is 22 minutes for heavy traffic. It decreases to 1.38 minutes and 0.5 minutes for medium and light traffic respectively. These values are consistent with the real system, therefore, simulation model is validated to represent the real system accurately.

\section{Computational results}

To get the computational results for the experimental design parameters, the simulation model is run for 12 hours period with a 2 hours warm-up limit. The observed hours of the traffic intensity do not reach up to 12 hours, however we want to run the simulation model as wide as we can achieve steady state results. The defined 2 hours warm-up limit is the maximum warm-up limit determined for all the traffic intensity alternatives and this warm-up period also eliminates the statistics of the vehicles that do not shows the effects of the determined traffic intensity. Each experimental design point is replicated 10 times and totally, 486 design points $\times 10$ replications $=4860$ simulation runs are performed.

\subsection{Effect of red signal length on "time in system"}

When the results are examined, firstly it is realized that red signal times have a direct effect on the time spent in system as expected. The shorter red signal is the less time spent in system. This can be seen in Figure 3 below.

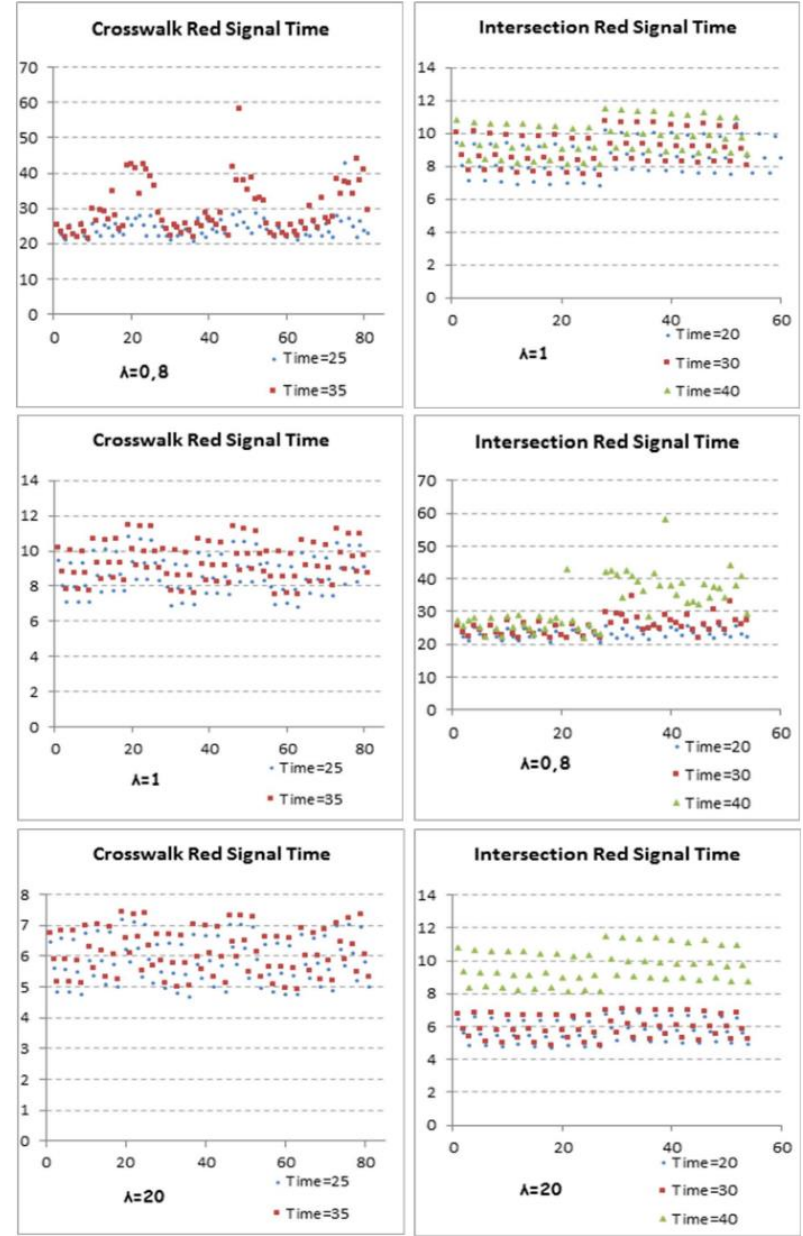

Figure 3: Effect of red signal length on "time in system".

In Figure 3, for all three traffic intensity levels, time in system is smaller when red signal time is smaller. This is also proved by making a hypothesis test at 95\% significance level. Different red light times are compared for each level of traffic intensity. The results of the statistical analysis can be seen in Table 7. In Table 7:

Time in system when red light length is 25 seconds at crosswalks,

$\mu 2$ : Time in system when red light length is 35 seconds at crosswalks,

t1 : Time in system when red light length is 20 seconds at intersections,

t2 : Time in system when red light length is 30 seconds at intersections,

t3 : Time in system when red light length is 40 seconds at intersections,

CI : Confidence Interval.

It can be seen clearly from Table 7 that as red light time decreases, time in system decreases. Therefore, red signal times are set to be the minimum possible level. In other words, crosswalk red signal time and intersection red signal time are determined to be $25 \mathrm{sec}$. and $20 \mathrm{sec}$. respectively.

After setting crosswalk and intersection red light times, number of factors to be analyzed is decreased to three which are crosswalk green light time, intersection green light time and speed. 
Table 6: Validation of the simulation model.

\begin{tabular}{cccccccc}
\hline & \multicolumn{2}{c}{ Time in System (min.) } & \multirow{2}{*}{$\begin{array}{c}\text { Average passing time from a } \\
\text { signal (min.) }\end{array}$} & \multicolumn{3}{c}{ Waiting time in redlight (min.) } \\
\cline { 2 - 3 }$\lambda$ & Average & Point A to Point B & 27 & 1.17 & Average & Minimum & Maximum \\
\hline 0.8 & 22 & 18 & 0.4 & 0.67 & 0 & 22 \\
1 & 13 & 15.26 & 0.15 & 0.11 & 0.13 & 0 & 1.38 \\
20 & 10.46 & 27 &
\end{tabular}

Table 7: Comparison of different red light times in terms of total time spent in system.

\begin{tabular}{ccc}
\hline & & Comparison of red light time for crosswalk \\
\hline$\lambda=0.8$ & CI for $(\mu 1-\mu 2)$ & Result at $95 \%$ significance \\
$\lambda=1$ & $(-6.86 ;-3.42)$ & $\mu 1$ is at least 3.42 minutes and at most 6.86 minutes less than $\mu 2$ \\
$\lambda=20$ & $(-1.03 ;-0.36)$ & $\mu 1$ is at least 0.36 minutes and at most 1.03 minutes less than $\mu 2$ \\
\hline & $(-0.51 ;-0.05)$ & $\mu 1$ is at least 0.05 minutes and at most 0.51 minutes less than $\mu 2$ \\
\hline & & Comparison of red light time for intersection \\
$\lambda=0.8$ & $(-3.05 ;-1.32)$ & Result at $95 \%$ significance \\
$\lambda=1$ & $(-0.98 ;-0.20)$ & t1 is at least 1.32 minutes and at most 3.05 minutes less than $\mathrm{t} 2$ \\
$\lambda=20$ & $(-0.54 ;-0.01)$ & $\mathrm{t} 1$ is at least 0.01 minutes and at most 0.54 minutes less than $\mathrm{t} 2$ \\
\hline & $\mathrm{CI}$ for $(\mathrm{t} 2-\mathrm{t} 3)$ & $\mathrm{t} 2 \mathrm{t} 2<\mathrm{t} 2$ \\
$\lambda=0.8$ & $(-8.90 ;-4.47)$ & $\mathrm{t} 2$ is at least 4.47 minutes and at most 8.9 minutes less than $\mathrm{t} 3$ \\
$\lambda=1$ & $(-1.05 ;-0.27)$ & $\mathrm{t} 2$ is at least 0.27 minutes and at most 1.05 minutes less than $\mathrm{t} 3$
\end{tabular}

\subsection{Standardized effects of design variables on different performance measures}

In the next step, three different performance measures are determined to be analyzed. These are time in system (TIS), waiting time in red light (WTIRL) and number of vehicles going out of the system (OUT). Effect of the three design variables, which are crosswalk green light (CGL), intersection green light (IGL) and speed, on the three performance measures are examined. Standardized effect graphs are drawn using MINITAB 17.3.1 trial version [16] and can be seen in Appendix. In figures, main effects $A, B$ and $\boldsymbol{C}$ stand for crosswalk green light, intersection green light and speed respectively.

In the Appendix, figures (a),(d) and (g) give the standardized effects of design variables on TIS. Secondly, figures (b),(e) and (h) show the effects on WTIRL. Finally, in figures (c),(f) and (i), effects on OUT performance measure are given.

Firstly, the reader can notice in figures (c) and (f), none of the main effects and interactions have a significant influence on the number of vehicles going out of the system. In addition, in figure (i), only interaction of factors A and B is found to be effective. This tells us that nearly none of the design parameters are effective on the number out. This result is also consistent with the fact that number out heavily depends on number in (traffic intensity). Therefore, the other two performance measures (TIS and WTIRL) are determined to be more important for the system performance and further analysis is carried out on these two measures.

In addition, from figures (a),(d) and (g), it can be seen that in all levels of traffic intensity, TIS is mainly affected by factor $\mathrm{C}$ and A. However, there are more effective variables on WTIRL. From figures (b),(e) and (h), factors A, B, C and interaction of B and C are found to be affecting WTIRL.

\subsection{Regression analysis on TIS and WTIRL}

After analyzing main and interaction effects on performance measures, regression analysis is carried out on the two performance measures TIS and WTIRL. Regression equations and coefficient of correlations $\left(\mathrm{R}^{2}\right)$ can be seen in Table 8 .

Looking at Table 8 , it can be seen that correlation coefficients belonging to TIS are very meaningful (close to 1). However, these values are rather small for WTIRL. This shows us that TIS is highly correlated with the design variables studied. Therefore, in order to set the final values for the design variables, TIS is considered.

Among the 486 design points simulated, the minimum TIS values for each of traffic intensity $(\lambda)$ levels are given in Table 9. For heavy traffic, TIS is found to be 20.83 minutes when CRL, IRL, CGL, IGL and speed values are $25 \mathrm{sec}, 20 \mathrm{sec}, 50 \mathrm{sec}$, $60 \mathrm{sec}$ and $833 \mathrm{~m} / \mathrm{min}(50 \mathrm{~km} / \mathrm{h})$ respectively. For medium traffic intensity TIS is found to be 6.84 minutes and for light traffic, TIS is found to be 4.70 minutes.

\subsection{Determining the best levels of design variables}

The best level of design variables are found among 486 points. However, there can be a better solution around these design points. In order to explore this solution area, OptQuest for ARENA [17] is used. In Table 10, the minimum and maximum levels of each design point and the increment size can be seen. For heavy traffic, the minimum for CGL is found to be $50 \mathrm{sec}$. from experimental design (Table 9). In OptQuest for ARENA [17], values between $45 \mathrm{sec}$. and $55 \mathrm{sec}$. increasing by $1 \mathrm{sec}$. are 
simulated (Table 10). Similarly, for heavy traffic, the minimum for IGL is found to be $60 \mathrm{sec}$. from experimental design (Table 9). In OptQuest for ARENA [17], values between 55 sec. and $65 \mathrm{sec}$. increasing by $1 \mathrm{sec}$. are simulated (Table 10). 100 iterations are made in OptQuest for ARENA [17]. The results obtained can be seen in Table 11.

In Table 11, best performing values for design variables and the corresponding TIS value can be seen. The bold and underlined values are determined to be the best levels of design variables. In result, for heavy traffic intensity, CRL, IRL, CGL, IGL and speed values are recommended to be $25 \mathrm{sec}$., $20 \mathrm{sec}$., $49 \mathrm{sec}$., 65 sec. and $960 \mathrm{~m} / \mathrm{min} .(\sim 58 \mathrm{~km} / \mathrm{h})$ respectively. In this case, average time in system for a vehicle will be 15.5 minutes which provides 29.5\% improvement compared to current performance (current performance is given in Table 6) and $25.58 \%$ improvement compared to experimental design best point. Similarly, for medium and light traffic intensities, results given in Table 11 provides $54.8 \%$ and $55.8 \%$ improvement compared to current performance of the system (Figure 4).

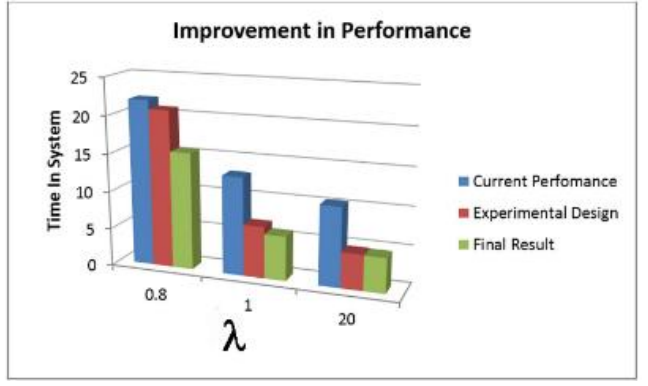

Figure 4: Improvement obtained in TIS performance.

\section{Conclusion}

In this study, traffic flow in a real urban area located in a major metropolis of Turkey is considered. The road is $6.7 \mathrm{~km}$ long with six intersections and six crosswalk signals. This is a complex network and constitutes an important part of the traffic congestion in the city.

Table 8: Regression analysis of design variables on TIS and WTIRL.

\begin{tabular}{|c|c|c|c|c|}
\hline \multirow{2}{*}{$\lambda$} & \multicolumn{2}{|l|}{ Time in System (TIS) } & \multicolumn{2}{|l|}{ Waiting Time in RedLight (WTIRL) } \\
\hline & RegressionEquation & $\mathrm{R}^{2}(\%)$ & RegressionEquation & $\mathrm{R}^{2}(\%)$ \\
\hline 0.8 & $\begin{array}{l}\text { TIS }=54.8-0.56 \mathrm{~A}-0.37 \mathrm{~B}-0.049 \mathrm{C} \quad+0.01 \mathrm{~A}^{*} \mathrm{~B} \\
+0.000864 \mathrm{~A}^{*} \mathrm{C}+0.000593 \mathrm{~B}^{*} \mathrm{C} \quad-0.000014 \mathrm{~A}^{*} \mathrm{~B}^{*} \mathrm{C}\end{array}$ & 84.69 & $\begin{array}{l}\text { WTIRL }=1.72-0.034 \mathrm{~A}-0.028 \mathrm{~B}-0.003 \mathrm{C} \\
\quad+0.0006 \mathrm{~A}^{*} \mathrm{~B} \\
+0.000057 \mathrm{~A}^{*} \mathrm{C}+0.000047 \mathrm{~B}^{*} \mathrm{C} \\
-0.000001 \mathrm{~A}^{*} \mathrm{~B}^{*} \mathrm{C}\end{array}$ & 49.69 \\
\hline 1 & $\begin{array}{l}\text { TIS }=13.21+0.034 A+0.020 B-0.00612 C \\
-0.00083 A^{*} B-0.000035 A^{*} C-0.000014 B^{*} C \\
+0.000001 A^{*} B^{*} C\end{array}$ & 98.24 & $\begin{array}{l}\text { WTIRL }=0.11-0.00021 \mathrm{~A} \\
-0.00096 \mathrm{~B}-0.000017 \mathrm{C}\end{array}$ & 92.78 \\
\hline 20 & $\begin{array}{l}\text { TIS }=7.72+0.034 \mathrm{~A}+0.074 \mathrm{~B}-0.00183 \mathrm{C} \\
-0.00108 \mathrm{~A}^{*} \mathrm{~B}-0.000037 \mathrm{~A}^{*} \mathrm{C}-0.000076 \mathrm{~B}^{*} \mathrm{C} \\
\quad+0.000001 \mathrm{~A}^{*} \mathrm{~B}^{*} \mathrm{C}\end{array}$ & 98.12 & $\begin{array}{l}\text { WTIRL }=0.033-0.00157 \mathrm{~A}+0.00284 \mathrm{~B} \\
+0.000062 \mathrm{C}-0.000014 \mathrm{~A}^{*} \mathrm{~B}+0.000001 \mathrm{~A}^{*} \mathrm{C} \\
-0.000003 \mathrm{~B}^{*} \mathrm{C}\end{array}$ & 77.35 \\
\hline
\end{tabular}

Table 9: Minimum level of "time in system" among 486 simulation experiments.

\begin{tabular}{ccccccc}
\hline$\lambda$ & CRL (sec.) & IRL (sec.) & CGL (sec.) & IGL (sec.) & Speed (m/min) & $\begin{array}{c}\text { Time InSystem } \\
(\mathrm{min} .)\end{array}$ \\
\hline 0.8 & 25 & 20 & 50 & 60 & 833.3 & 20.83 \\
1 & 25 & 20 & 60 & 60 & 1000 & 6.84 \\
20 & 25 & 20 & 50 & 60 & 1166.6 & 4.70 \\
\hline
\end{tabular}

Table 10: Limits for the search around the minimum point found in experimental design.

\begin{tabular}{cccccccccc}
\hline \multirow{2}{*}{$\lambda$} & \multicolumn{3}{c}{ CGL (sec.) } & \multicolumn{3}{c}{ IGL (sec.) } & \multicolumn{2}{c}{ SPEED (m/min.) } \\
\cline { 2 - 10 } & Min & Max & Increment & Min & Max & Increment & Min & Max & Increment \\
\hline 0.8 & 45 & 55 & 1 & 55 & 65 & 1 & 666.6 & 1000 & 20 \\
1 & 55 & 65 & 1 & 55 & 65 & 1 & 833.3 & 1166.6 & 20 \\
20 & 45 & 55 & 1 & 55 & 65 & 1 & 833.3 & 1166.6 & 20 \\
\hline
\end{tabular}

Table 11: Best performing points found by OptQuest for ARENA [17].

\begin{tabular}{|c|c|c|c|c|c|c|c|c|}
\hline & $\lambda$ & CRL (sec.) & $\begin{array}{c}\text { IRL } \\
\text { (sec.) }\end{array}$ & $\begin{array}{l}\text { CGL } \\
\text { (sec.) }\end{array}$ & IGL (sec.) & SPEED $(\mathrm{m} / \mathrm{min})$ & TIS (sec) & $\begin{array}{c}\text { Improvement } \\
(\%)\end{array}$ \\
\hline Min. DP Value & 0.8 & 25 & 20 & 50 & 60 & 833 & 20,83 & \multirow{2}{*}{25.58} \\
\hline Optquestfor ARENA & $\underline{0.8}$ & $\underline{25}$ & $\underline{20}$ & $\underline{49}$ & $\underline{65}$ & $\underline{960}$ & $\underline{15.50}$ & \\
\hline Min. DP Value & 1 & 25 & 20 & 60 & 60 & 1000 & 6.84 & \multirow{2}{*}{14.04} \\
\hline Optquestfor ARENA & $\underline{1}$ & $\underline{25}$ & $\underline{20}$ & $\underline{59}$ & $\underline{64}$ & $\underline{1166.6}$ & $\underline{5.88}$ & \\
\hline Min. DP Value & 20 & 25 & 20 & 50 & 60 & 1166.6 & 4.70 & \multirow{2}{*}{1.70} \\
\hline Optquestfor ARENA & $\underline{20}$ & $\underline{25}$ & $\underline{20}$ & $\underline{49}$ & $\underline{63}$ & $\underline{1166.6}$ & $\underline{4.62}$ & \\
\hline
\end{tabular}


The objective is decreasing unnecessary delay times for vehicles as well as increasing the throughput. In order to do so, $\mathrm{red} /$ green signal times and speed of vehicles must be set correctly.

Firstly, current traffic flow is simulated using ARENA 14.0 [15]. Then six design factors are defined. These are traffic intensity, crosswalk red light time, crosswalk green light time, intersection red light time, intersection green light time and speed of vehicles. For different levels of the design factors, an experimental design frame is built. 486 design points are simulated. Throughput of the system, total waiting time and total time in system are recorded for each of the design points. Then various statistical analysis are carried out. Significant effects and correlations are identified between the design variables and performance measures. Then a local area search is carried out. Finally, using these results, best operating levels of vehicle speed and signal times are found for the three levels of traffic intensity separately.

\section{References}

[1] Febbraro AD, Sacco N. "On evaluating traffic lights performance sensitivity via hybrid systems models". Procedia-Social and Behavioral Sciences, 111, 272-281, 2014.

[2] Papageorgiou M, Diakaki C, Dinopoulou V, Kotsialos A, Wang Y. "Review of road traffic control strategies". Proceedings of the IEEE, 91(12), 2043-2067.2003.

[3] Mitsakis E, Salanova JM, Giannopoulos G. "Combined dynamic traffic assignment and urban traffic control models". Procedia Social and Behavioral Sciences, 20, 427-436, 2011.

[4] Araghi S, Khosravi A, Creighton D. "A review on computational intelligence methods for controlling traffic signal timing". Expert Systems with Applications, 42, 1538-1550, 2015.

[5] Boumediene, A, Brahimi K, Belguesmia N, Bouakkaz K. "Saturation flow versus green time at two-stagesignal controlled intersections". Transport, 24(4), 288-295, 2009.
[6] Babicheva TS, Babichev DS. "Numerical methods for modeling of traffic flows at research and optimization of traffic on the signal controlled road intersections". Procedia Computer Science, 55, 461-468, 2015.

[7] Mirchandani P, Head L. "A real-time traffic signal control system: architecture, algorithms, and analysis". Transportation Research Part C, 9(6), 415-432, 2001.

[8] Jahangiri A, Afandizadeh S, Kalantari N. "Theotimization of traffic signal timing for emergency evacuation using the simulated annealing algorithm". Transport, 26(2), 133-140. 2011.

[9] Pranevicius H, Kraujalis, T. "Knowledge based traffic control model for signalized intersection". Transport 27(3), 263-267, 2012.

[10] Varia HR, Gundaliya PJ, Dhingra SL. "Application of genetic algorithms for joint optimization of signal setting parameters and dynamic traffic assignment for the real network data". Reseach in Transportation Economics, 38(1), 35-44, 2013.

[11] Jeihani M, James P, Saka AA, Ardeshiri A. "Traffic recovery time estimation under different flow regimes in traffic simulation". Journal of Traffic and Transportation Engineering (English Edition), 2(5), 291-300, 2015.

[12] Hu W, Wang H, Du B, Yan L. "A Multi-Intersection Model And Signal Timing Plan Algorithm For Urban Traffic Signal Control". Transport, 32(4), 368-378, 2017.

[13] Grether D, Neumann A, Nagel K. "Simulation of urban traffic control: a queue model approach". Procedia Computer Science, 10, 808-814, 2012.

[14] BabichevaTS. "The use of queuing theory at research and optimization of traffic on the signal-controlled road intersections". Procedia Computer Science 55, 469-478.2015.

[15] Arena 14.0, Rockwell Automation Inc, 2012.

[16] Minitab 17.3.1, Minitab, Inc., 2016.

[17] OptQuest for ARENA 6.4, OptTek Systems Inc., 2006.

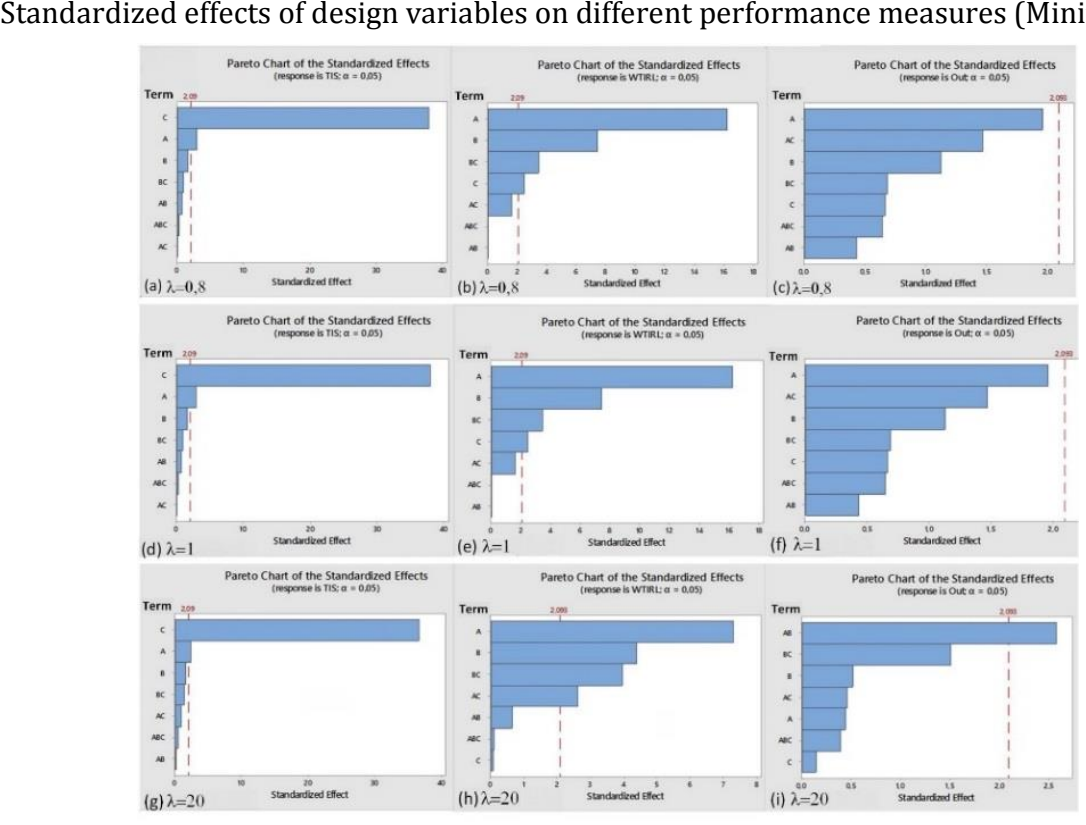

